British Journal of Psychology (2003), 94, 457-473

(c) 2003 The British Psychological Society

\title{
Reassessing the dimensionality of the moral emotions
}

\author{
Nathan Harris* \\ Institute of Criminology, University of Cambridge, UK
}

\begin{abstract}
The dimensionality of the moral emotions was tested to examine whether theoretical distinctions between specific emotions were empirically supported. A total of 720 drink-driving offenders indicated the degree to which they experienced feelings associated with the moral emotions, in an interview conducted after attending court or a restorative justice conference. Expected distinctions between shame and guilt were not found. Instead the principal components analysis identified three factors: shame-guilt, embarrassment-exposure, and unresolved shame. The results also show that shame-guilt was related to higher feelings of empathy and lower feelings of anger/ hostility. It is concluded that differences between shame and guilt may be overstated. Furthermore, it is suggested that the relationship between situational experiences of shame and the disposition to feel it may be more complicated than initially thought.
\end{abstract}

One consequence of failing to live up to personal or social values is to experience negative emotion. Research in psychology and related disciplines has highlighted the importance of emotions in mediating individuals' behaviour and psychological wellbeing following the transgression of norms (Braithwaite, 1989; Nathanson, 1992; Scheff \& Retzinger, 1991; Tangney, 1991). Interest in these 'moral' emotions is not new. Guilt came to prominence in psychology partly through Freud's (1949/1930) psychoanalytic theory, which gave it a central role in explaining the underlying causes of neurosis. Anthropologists have also used the emotions of shame and guilt to describe differences in the way societies regulate compliance with rules (Benedict, 1946; Mead, 1937). Evidence that emotions may be critical to how individuals react to failure has prompted psychologists to re-examine the moral emotions. Whereas some people are able to recognize that things have gone wrong, attempt to repair the situation and move on, others react by wzithdrawing, placing blame on others, or feeling depressed and helpless. Key questions posed are whether these reactions are mediated by different affects and, if so, which affects result in constructive as opposed to destructive responses.

\footnotetext{
* Requests for reprints should be addressed to Dr Nathan Harris, Institute of Criminology, University of Cambridge, 7 West Road, Cambridge CB3 9DT (e-mail: nathan.harris@crim.cam.ac.uk).
} 


\section{Distinctions between shame and guilt}

Various distinctions between shame and guilt have been proposed by scholars in a variety of disciplines. Despite this, it is possible to identify a number of broad approaches. The first of these is based upon the idea that guilt is a response to the violation of internal norms, whereas shame is a response to (or fear of) criticism or disapproval by others (Benedict, 1946; Gibbons, 1990; Gilbert, 1997; Leary, 2000; Mead, 1937). For Gibbons (1990), this distinction results from the hypothesis that individuals oscillate between self and other awareness (Duval \& Wicklund, 1972). When individuals are self-aware, they are motivated to conform to personal values. Guilt is the emotional response to the realization of having violated these values. In contrast, when an individual's attention is externally focused, they are motivated to conform to others' values, and shame occurs when it is perceived that they have not. A similar distinction between shame and guilt is evident in evolutionary approaches (Gilbert, 1997), which argue that shame is based upon a need to be attractive to others (a determinant of social status), whereas guilt is based upon an empathic desire to look after others. Other scholars argue that shame is particularly associated with disapproval or criticism by others because it is a response to the perception that one's relationship with others is threatened (Leary, 2000; Scheff \& Retzinger, 1991).

Although empirical results suggest that shame may have stronger links to the social context, they have not strongly supported a distinction between shame and guilt based upon the source of evaluation (Epstein, 1984; Lindsay-Hartz, 1984; Wallbott \& Scherer, 1995). For example, Wicker, Payne, and Morgan (1983) found that participants' descriptions of shame, when compared to their descriptions of guilt, were characterized by greater feelings of exposure, a greater desire to hide, and feelings that others were more rejecting. There was no difference between emotions, however, on items measuring concern with 'how others saw me' or where negative evaluation was coming from. These results were replicated using a similar methodology by Tangney, Miller, Flicker, and Hill-Barlow (1996), with the exception that when intensity was controlled for shame, experiences involved a stronger focus on other's thoughts. Researchers have also consistently found that people report feeling shame in the absence of others (Piers \& Singer, 1953; Tangney, Miller et al., 1996) which suggests that external evaluation is not necessary.

An alternative approach to distinguishing these emotions proposes that shame occurs when negative evaluation is directed towards the self, whereas guilt occurs when negative evaluation is restricted to one's actions (H. Lewis, 1971; M. Lewis, 1992; Lindsay-Hartz, 1984; Tangney, 1991). A number of perspectives argue that this is because guilt is more closely associated with transgression, the breaking of rules, but that shame is more closely associated with failure, the perception of not having lived up to one's ideals (H. Lewis, 1971; Piers \& Singer, 1953; Wurmser, 1994). Other scholars accept that shame is a more global emotion than guilt but do not associate this with a fundamental difference between transgression or failure. For example, M. Lewis (1992) proposes that the distinction simply reflects a difference in the attribution of failure: shame is a global attribution of failure to the whole self, whereas guilt is a specific attribution of failure to a particular action.

Comparisons between shame and guilt based upon the object of these emotions (the self vs. the behaviour), have also received mixed support from empirical studies. Wicker et al. (1983) tested the distinction by asking participants whether they felt ' . . unhappy with myself in general (vs. only with my behaviour)' during previous experiences of 
each emotion. No significant difference was found between people's memories of shame and guilt. A similar result is reported by Tangney, Miller et al. (1996), who found no difference in the degree to which participants recalled "blam[ing] my actions and behaviour" versus "blam[ing] my personality and my self" (p. 1265). It was suspected by researchers that questions measuring this dimension are simply too abstract for most people. To overcome these difficulties, Niedenthal, Tangney, and Gavanski (1994) used a counterfactual thinking paradigm that assessed which elements people choose to change in order to rectify negative experiences. The results supported the hypothesized distinction between shame and guilt. Respondents nominated aspects of the self in shame experiences more often than they did in guilt experiences. Equally, participants nominated situational factors in guilt experiences more often than in shame experiences. The results also underlined the subtlety of this distinction, with participants nominating transient characteristics of the self more often than chronic characteristics, even when shame was the reported emotion.

Although many theoretical approaches describe shame as distinct from guilt on at least one of the two dimensions described above (the source or object of the emotions), empirical studies demonstrate only limited support for either. This is consistent with a third perspective, that of affect theory (Nathanson, 1992; Tomkins, 1987), which argues that both emotions (and embarrassment) result from the same underlying physiological affect (shame-humiliation). Although this suggests that there should be considerable similarity between these emotions, application of the theory also recognizes that individuals develop distinct cognitive and behavioural scripts that are associated with each affect (Kaufman, 1996; Nathanson, 1992, 1997). Thus, affect theory does not preclude social distinctions between emotions like shame and guilt, although it does not predict any either.

\section{Implications of feeling shame and guilt}

Researchers have become increasingly interested in understanding the impact of the moral emotions, and it is within this field of research that possible differences between shame and guilt seem more pronounced. Building upon one of the distinctions discussed above (that the objects of shame and guilt are different), Tangney and her colleagues hypothesize that individuals who are prone to feel shame will cope with failure less adaptively, because its intense focus on negative aspects of the self is much more painful and crippling (Tangney, 1991). In comparison, it is hypothesized that a disposition to feel guilt results in more adaptive and reparative behaviours, because the individual's attention is focused on the harm done to others. Studies by Tangney and her colleagues using the Test of SelfConscious Affect (TOSCA: Tangney, Wagner, \& Gramzow, 1989) have supported these predictions. Tangney (1991) found in a sample of undergraduate students that a proneness to feel shame was negatively correlated with the disposition to feel other-oriented empathy, but that guilt-proneness was positively related to empathy. Studies have also found that shame-proneness, but not guilt-proneness, is positively correlated with measures of how prone individuals are to externalize blame, feel anger/hostility (Tangney, Wagner, Fletcher, \& Gramzow, 1992) and react to events in an aggressive and less constructive manner (Tangney, Wagner, Hill-Barlow, Marschall, \& Gramzow, 1996).

Although Tangney's TOSCA instrument has reliably distinguished between the correlates of shame- and guilt-proneness, its measurement of these constructs has also 
been questioned (Harder, 1995; Sabini \& Silver, 1997). It is argued that the TOSCA overemphasizes negative self-evaluation in the case of shame-proneness, but underemphasizes it in the case of guilt-proneness. According to Harder (1995), this explains findings that shame is a problematic, and perhaps a dysfunctional, emotion, whereas guilt is not associated with psychological symptoms such as depression (Harder, 1995; Harder, Cutler, \& Rockart, 1992). These criticisms are reflected in studies which show that Harder's guilt-proneness scale (Harder, 1995), unlike the TOSCA guilt scale, is correlated with a number of psychological symptoms, including depression, self-derogation and hostility -anger.

The current debate on the relationship of guilt- and shame-proneness to psychopathology again highlights uncertainty as to how the emotions should be distinguished. Tangney and her colleagues' findings demonstrate important differences between individuals who respond to transgressions with strong negative self-evaluation and those who tend to focus on their actions and the harm done to others. The question posed by Harder and others is whether this difference reflects a distinction between the propensity to feel shame or guilt.

\section{Comparisons with embarrassment}

Whereas comparisons between shame and guilt have dominated research on the moral emotions, embarrassment may define a third common reaction to non-compliance with norms. Indeed, its apparent prevalence in social life means that it is difficult to compare conceptions of shame and guilt without considering it. Again, however, the relationship between embarrassment and shame has been characterized in a variety of ways. Some theorists consider embarrassment as simply a less intense form of shame (Kaufman, 1996; Nathanson, 1992; Scheff, 1990; Tomkins, 1987). The primary alternatives to this view are that embarrassment is a reaction to the violation of non-moral norms or is a result of social anxiety. For example, Harré (1990) argues that shame and embarrassment can be contrasted on two dimensions: seriousness and fault. Thus, embarrassment is described as an emotion that results from an accidental breaking of a social etiquette. A similar perspective is that embarrassment is social anxiety, caused by either a perceived inability to respond appropriately to the situation or the fear that others will make negative judgements about the self (Buss, 1980; Crozier, 1990; Edelmann, 1987; Edelmann et al., 1989; Miller, 1992, 1995; Taylor, 1985). The implication of these perspectives is that embarrassment, unlike shame, is social anxiety that occurs in a particular context rather than the awareness of having violated important or ethical norms.

These observations have been supported by studies (Miller \& Tangney, 1994; Tangney, Miller et al., 1996; but see Sabini, Garvey, \& Hall, 2001) which show that participants remember experiences of embarrassment, in comparison to shame, as more often caused by accidents, as less related to moral standards, as less serious, of shorter duration and occurring more often only because others knew 'about it'. Significantly, differences between shame and embarrassment remained even when intensity was controlled for (Tangney, Miller et al., 1996), which supports the hypothesis that they are distinct emotional experiences. Although these studies separate shame and embarrassment, they also demonstrate similarities between embarrassment and conceptions of shame, particularly early anthropological approaches, which emphasize the importance of disapproval by others. 


\section{The present study}

The present study re-examines the relationship between the moral emotions using a factor-analytic approach. By asking participants to indicate the degree to which they recalled specific feelings (e.g. anger at the self) in a recent situation (a drink-driving case), it was possible to use principal components analysis to test the structure of these emotions. This technique has not yet been applied to these emotions, but is particularly useful for testing the dimensionality of concepts where theory or measurement is not well developed (Tabachnick \& Fidell, 2001). Although various predictions regarding these emotions have been discussed, they give only partial descriptions of the whole domain, thus making confirmatory analysis difficult without considerable post boc modification. Undetermined or contentious issues include the number of factors required, which groups of variables would primarily define these factors and the location of peripheral or less well-understood variables in the model. Measures of the feeling items were also newly developed, and thus little was known about their reliability or validity. As a result, principal components analysis was used to reduce measures of specific feelings to interpretable components that should provide evidence about the underlying structure.

This methodology departs substantially from much of the previous research on the moral emotions, which has asked participants to recall, or imagine, experiences of shame, guilt or embarrassment and then report what they felt, or would have felt (Lindsay-Hartz, 1984; Miller \& Tangney, 1994; Niedenthal et al., 1994; Tangney, Miller et al., 1996; Wallbott \& Scherer, 1995; Wicker et al., 1983). What such studies show is that people conceive of these emotions differently: the characteristics they associate with recalled shame experiences are different from those associated with guilt and embarrassment experiences. However, as Wicker et al. (1983) point out, it is unclear whether these conceptual differences reflect a distinction in the feelings that are experienced. Even though participants may recall feeling guilt in one situation and shame in another, were the feelings at the time different? Or are they simply recalled as different because of pre-existing conceptions of shame, guilt and embarrassment? Although the measures used in this study are also retrospective, they asked about a specific incident that had recently occurred. This meant that respondents were not asked to describe emotions but simply to indicate the degree to which they experienced particular feelings (e.g. 'feeling angry with myself'). It was then possible to explore the structure of these feelings empirically.

In previous research (Tangney, 1991; Tangney et al., 1992), measures of shame and guilt proneness have been found to correlate with empathy and anger/hostility. Testing the relationship between the situational emotion factors identified in this study and empathy and anger/hostility was carried out to further define the factors as well as to allow comparison to dispositional measures of shame and guilt.

\section{Method}

\section{Participants}

A sample of 900 individuals apprehended for driving with a blood alcohol content over .08 were included in the study (the legal alcohol limit in Australia is .05). Of these, 720 were interviewed afterwards. The mean age was 30 years and $76 \%$ were male. Interviews of participants were not obtained in those cases where the criminal justice intervention was not completed, where the participant did not consent, or where participants could not be located for interviewing. 


\section{Procedure}

The data reported here were collected as part of a larger experiment ${ }^{\mathbf{1}}$ into the effectiveness of criminal justice interventions that follow the apprehension of drivers with a blood alcohol level greater than the legal limit. The two criminal justice interventions studied were traditional court proceedings and restorative justice conferences. ${ }^{2}$ Conferences are a relatively new criminal justice intervention that initially began in New Zealand but have spread to many parts of the world, including Australia, Belgium, Singapore, the USA and the UK. The intervention involves a meeting between those who have committed an offence and those who have been affected by it. In the type of cases studied, this usually included the offender, a group of people who cared for the offender, a community representative, and a trained police officer who facilitated the process. Each conference discussed the offence, its consequences, information about drink-driving, and ways in which the offender could make amends and avoid further offending. On average, these conferences took approximately one and a half hours. The court cases usually involved a reading of the facts by the prosecutor, a plea on behalf of the defendant, and sentencing by the magistrate. Sometimes an additional statement regarding the offence or personal circumstances was made by the defendant or their solicitor. On average, court cases took 7 minutes.

Both of these criminal justice interventions are specific events in participants' lives that involve the violation of a generally accepted social norm. To varying degrees, they also involved disapproval of the offence and discussion of how it had hurt others, or might have hurt others. It is reasonable to expect that participants could feel shame, guilt or embarrassment to varying degrees of intensity during these interventions, and thus they seemed an appropriate context in which to explore the dimensionality of these emotions. However, focusing upon a specific context like these drink-driving cases also means that the results may not represent the broad spectrum of situations in which these emotions occur.

Upon being apprehended with a blood alcohol level greater than .08 and having been nominated by the arresting officer (with consent from the supervising sergeant), participants were randomly allocated by researchers to either the court or conferencing conditions. In the court condition participants were required (via a summons or voluntary agreement to attend court) to attend a court case. This is the standard procedure where individuals are apprehended with a blood alcohol content over .08. The conference condition involved offering participants the choice of attending a conference case instead of court. Of the 450 participants offered a conference, only 7 refused, instead choosing to have their case taken to court. At this stage, participants were not made aware that the choice of attending a conference had been allocated randomly. This minimized the possible effects that this knowledge might have had on perceptions of the treatments, and was considered ethical because the result of randomization was either the standard outcome or a choice that involved the standard outcome.

Interviews with participants were sought 2-4 weeks after the case was finalized. On average, this interview occurred 40 days after the participant's last conference or court case (22 of the court cases and 4 of the conference cases required the participant to

\footnotetext{
'The Reintegrative Shaming Experiments (Sherman, Braithwaite, \& Strang, 1994) consist of four experiments that compare the effectiveness of court cases and restorative justice conferences conducted in the Australian Capital Territory for drink-driving, youth violence and juvenile property offences.

${ }^{2}$ Restorative justice conferences are also called family group conferences and diversionary conferences among other names. For the remainder of this article they will be referred to simply as conferences.
} 
attend on more than one occasion). The interview took approximately 1 hour 20 minutes and covered issues ranging from the participant's perception of whether they were treated fairly to how they felt during the case. This study focuses upon items that asked participants the degree to which they experienced characteristics associated with the moral emotions, feelings of empathy, and feelings of anger/hostility.

\section{Measures}

\section{Self-report measures of shame, guilt and embarrassment}

The moral emotions were measured by 23 items in a questionnaire that was selfcompleted by participants. Responses were recorded on 5-point scales indicating whether the participant experienced the feeling 'not at all' (1) or at the other extreme that they 'felt overwhelmed by it' (5). The means and standard deviations of these items are presented in Table 2 .

The items measuring the phenomenology associated with shame, guilt and embarrassment were developed based upon conceptualizations of these emotions found in the literature. Shame is associated by various conceptions with awareness that others are critical or derisive of oneself or one's actions (Benedict, 1946; Mead, 1937), fear of others' evaluations (Harré, 1990; Williams, 1993), feeling that one has lost honour (Taylor, 1985; Williams, 1993), feelings of being a failure (H. Lewis, 1971; M. Lewis, 1992; Piers \& Singer, 1953), self-directed anger and hostility (H. Lewis, 1971; Tangney, 1991; Wurmser, 1994), the feeling that one's whole self is shameful (H. Lewis, 1971; M. Lewis, 1992; Tangney, 1991), and the realization of being associated with something that is against one's ethical or moral standards (Harré, 1990; Taylor, 1985; Williams, 1993). Finally, a number of approaches suggest that a form of by-passed shame involves ongoing obsessive thoughts regarding the shameful situation, what occurred, its fairness, and how it relates to self (H. Lewis, 1971; Scheff, 1990).

Guilt is described by various conceptions as an emotion resulting from the individual's perception that they have done something wrong (Benedict, 1946; H. Lewis, 1971; Mead, 1937; Williams 1993); as having a specific focus upon a particular act or omission (H. Lewis, 1971; M. Lewis, 1992; Tangney, 1991); as involving feelings which are focused upon the damage that one has caused, particularly the recognition that one has hurt others (Baumeister, Stillwell, \& Heatherton, 1995; Tangney, 1991); and fear of punishment or retribution (Nathanson, 1992; Williams, 1993).

Embarrassment is associated with the knowledge that others are aware that one has breached a social convention (Harré, 1990), awareness of unwanted social attention, fear of evaluation by others (Crozier, 1990), feeling unsure of what to do in a particular situation, feelings of social awkwardness (Miller, 1995), feelings of being in the presence of others who have higher status (Sachdev, 1990), the feeling that one has jeopardized future opportunities (Grasmick \& Bursik, 1990) and, in extreme cases, feelings of humiliation (Crozier, 1990).

\section{Measurement of empathy and anger/hostility}

Measurement of empathy is needed in order to focus upon feelings in a specific context. As a result, two items were developed that focus upon the participants' emotional responsiveness to the hurt they may have caused others. These two Likert items were: 'During the conference/court case I found myself really affected by the emotions of those who had been hurt in some way' and 'In the conference/court case I began to 
understand what it actually felt like for those who had been affected by my actions'. The Cronbach's $\alpha$ for a scale consisting of these items was .68 for both court and conference cases.

Anger/hostility was measured by four Likert items that focused upon the specific context: 'You feel bitter about the way you were treated in the case', 'The conference/ court case just made you angry', 'You feel that the people who accused you in the conference/court case were more wrong than you were' and 'You wish you could get back at the people who were accusing you in the conference/court case'. The Cronbach's $\alpha$ for this scale was .69 for both court and conference cases.

\section{Results}

\section{The dimensionality of shame, guilt and embarrassment}

Table 1 shows correlations between the items measuring shame, guilt and embarrassment for court and conference cases. Preliminary analysis of these items revealed the same number of factors and similar item loadings in the two conditions. Consequently, data from both court and conference cases were included in a single principal components analysis. Three factors that explained $55 \%$ of the variance were extracted after consideration of three factors: (a) eigenvalues $>1$ (eigenvalues for the first five factors were: $8.28,2.56,1.37,0.97,0.93$ ), (b) a scree test and (c) the simple structure of the solution (Cattell, 1966; Gorsuch, 1983). Moderate correlations between factors (see Table 3) meant that they were rotated using the SPSS oblimin program. The rotated pattern matrix is presented in Table 2 .

The first factor had strong loadings for items expected to measure both shame and guilt. Feelings of being ashamed at what one had done, feeling ashamed of oneself, and feeling angry at oneself had strong loadings. However, so too did feelings of having done something that was wrong and feeling bad because one had, or might have, hurt others. These latter feelings have been strongly associated with guilt. There was also evidence that the factor was measured by feelings of having lost respect or honour among family and friends, concern that others knew about the offence, and fear of criticism.

Evidence that shame and guilt were measured by the same factor contrasts with a number of the theoretical perspectives discussed. Items measuring awareness of having done wrong were measured by the same factor as items measuring concern with others' reactions. This is contrary to the notion that the source of disapproval (self vs. other) would distinguish between these emotions. Evidence that shame and anger directed towards the self co-varied with concern directed at the act and its effects is also contrary to the idea that the object of the emotions (the self as opposed to the act or the other) is a definitive difference. ${ }^{3}$

The second factor was labelled 'unresolved shame' because items that loaded on this factor measure negative feelings from the case that were ongoing. These included feeling that some of the issues brought up had not been resolved, being bothered by thoughts that one was unfairly judged, and an inability to decide whether what one had done was wrong. The ongoing, obsessive nature of these thoughts is similar to the phenomenology of by-passed shame, as identified in the work of H. Lewis (1971) and Scheff and Retzinger (1991). In addition to these primary variables, there are moderate

\footnotetext{
${ }^{3}$ It is worth noting that when a fourth factor was extracted this did not result in a structure that represented the proposed distinctions and contributed little to the variance explained.
} 


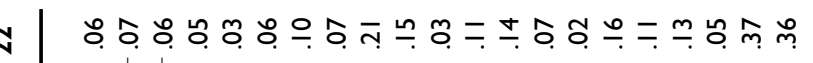

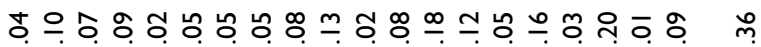

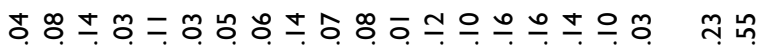

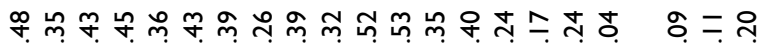

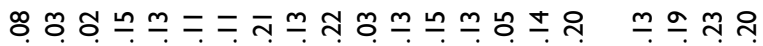

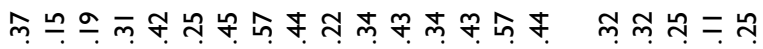

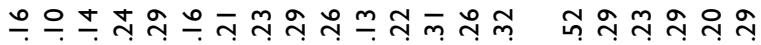

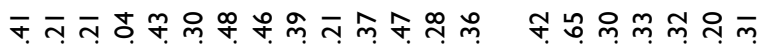

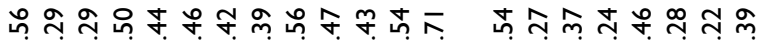
ซ. సุ

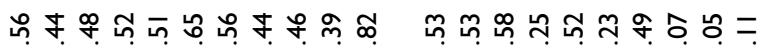

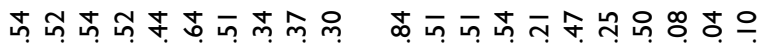

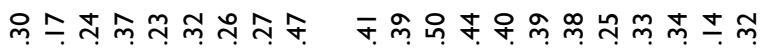

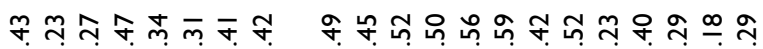

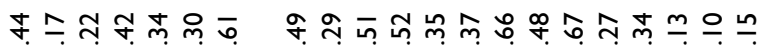

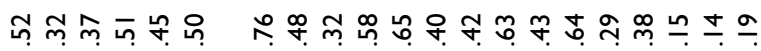

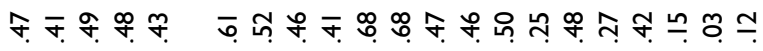

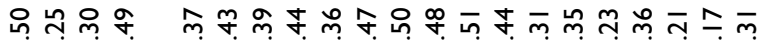

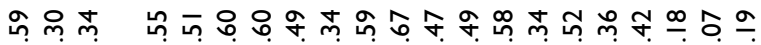

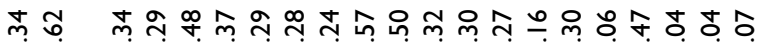

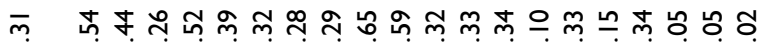

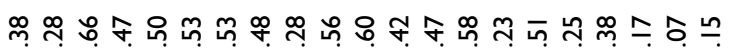

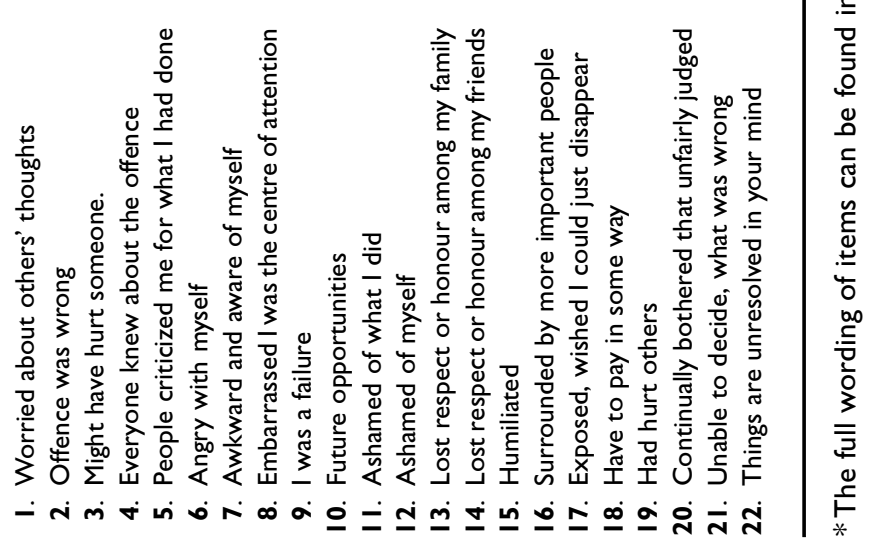


Table 2. Rotated pattern matrix of shame-related items

Items $(M, S D)$

I I. During the conference/court case I felt ashamed of what I did $(3.19,1.12)$

3. During the conference/court case I felt bad because the offence I committed might have hurt someone $(3.52,1.19)$

12. During the conference/court case I felt ashamed of myself $(2.80,1.27)$

19. I felt bad in the conference/court because my actions had hurt others $(2.24,1.22)$

2. During the conference/court case I felt that the offence I committed was wrong $(3.69,0.84)$

6. In the conference/court case I felt angry with myself for what I had done $(3.18,1.18)$

5. During the conference/court case I felt ashamed because people criticized me for what I had done $(2.09,1.15)$

I. During the conference/court case I felt worried about what others thought of me $(2.56,1.19)$

4. I felt bad in the conference/court case because everyone knew about the offence I had committed $(2.46, \mathrm{I} .2 \mathrm{I})$

14. During the conference/court case I felt like I had lost respect or honour among my friends $(1.64,0.91)$

13. During the conference/court case I felt like I had lost respect or honour among my family $(1.80,1.04)$

22. Do you feel that some of the things brought up in the conference/ court are unresolved in your mind? $(I .43,0.86)$

$2 \mathrm{I}$. Since the conference/court case have you found yourself unable to decide, in your own mind, whether or not what you did was wrong? I.34, 0.85)

20. Since the conference/court have you found yourself continually bothered by thoughts that you were unfairly judged by people at the conference/court case? $(1.42,0.86)$

10. During the conference/court case I felt that I had stuffed up at least some of my future opportunities $(2.03,1.14)$

17. During the conference/court case I felt so exposed, I wished I could just disappear $(2.00,1.20)$

8. In the conference/court I felt embarrassed because I was the centre of attention $(2.74,1.28)$

15. I felt humiliated in the conference/court $(2.07,1.14)$

7. During the conference/court case I felt awkward and aware of myself $(2.96,1.18)$

16. In the conference/court case I felt uneasy because I was surrounded by people who were supposed to be more important than me $(1.86,1.03)$

18. During the conference/court case I felt worried that I would have to pay in some way for the offence I committed $(2.60,1.21)$

9. During the conference/court case I felt that I was a failure $(1.60,0.96)$ 
loadings for items that appear to centre upon the offender's losses: lost respect and lost opportunities.

The last factor is defined by high loadings on items that measure embarrassment from being the centre of attention, feeling so exposed that one would like to disappear, and feeling humiliated. Other items measure feeling awkward and self-conscious, and feeling uneasy because one is surrounded by more important people than oneself. The items that define this factor all focus upon the respondent's discomfort in the situation due to unwanted social attention and can be best described as embarrassmentexposure. The difference between this factor and the shame-guilt factor is consistent with the proposed distinction between shame as a response to a serious transgression and embarrassment as social anxiety that occurs in a specific context. However, it is important to note that there is a considerable correlation between the shame-guilt and embarrassment-exposure factors (see Table 3).

Table 3. Pearson product-moment correlations between the emotion scales

Shame-guilt Embarrassment-exposure

$\begin{array}{lll}\text { Embarrassment-exposure } & .51^{* *} & \\ \text { Unresolved emotion } & .02 & .27^{* *}\end{array}$

Note. Scales were formed by summing the variables that loaded cleanly on each factor. Shame-guilt comprised items 2,3,6, II, I 2 and 19, Unresolved shame comprised items 20, 21, 22, and embarrassment-exposure comprised items $7,8,15,16$ and 17.

\section{Moral emotions, empathy and anger/hostility}

To test how the emotion factors relate to empathy and anger/hostility, two multiple regression analyses were performed, the results of which are presented in Table 4 . Of particular interest is the shame-guilt factor, which predicted greater feelings of empathy but lower anger/hostility. Surprisingly, this pattern of results is comparable to those found by Tangney (1991) and Tangney et al. (1992) for guilt-proneness and quite dissimilar to those found for shame-proneness. This is despite measurement of shame-guilt by items that represent both emotions, including feelings of shame and anger at the self. In contrast to shame-guilt, unresolved shame was a strong predictor of greater anger/hostility. In this respect, unresolved shame is consistent with predictions that shame can result in aggression (Nathanson, 1992, Tangney et al., 1992), particularly when unacknowledged or by-passed (H. Lewis, 1971; Scheff \& Retzinger, 1991). Unresolved shame was also associated with greater empathy, though quite weakly. Finally, embarrassment - exposure was associated with greater feelings of anger/hostility, though the relationship was not as strong as that observed for unresolved shame, and did not predict feelings of empathy. These results suggest that it is important to distinguish between shame-guilt and embarrassment-exposure despite the strong correlation between them.

\section{Discussion}

The results indicate that shame and guilt were not distinguishable in participants' memories of attending a criminal justice case. Characteristics seen as theoretically 
Table 4. $\beta$ weights for the regression on empathy and on anger/hostility

\begin{tabular}{lcc}
\hline Variable & Empathy & Anger/hostility \\
\hline Controls & & \\
$\quad$ Treatment type & $.32^{* *}$ & $-.14^{* *}$ \\
Shame-related emotions & & \\
Shame-guilt & $.58^{* *}$ & $-.24^{* *}$ \\
Embarrassment-exposure & .05 & $.12^{* *}$ \\
Unresolved shame & $.10^{* *}$ & $.41^{* *}$ \\
Treatment by main effect interactions & & -.02 \\
Treatment $\times$ shame-guilt & $.07^{*}$ & .00 \\
Treatment $\times$ embarrassment-exposure & .01 & -.03 \\
Treatment $\times$ unresolved shame & -.03 & 1.95 \\
Constant & 2.33 & $.29 * *$ \\
Adjusted $R^{2}$ & $.57^{* *}$ & \\
\hline
\end{tabular}

$* p<.05, * * p<.01$.

important in comparisons of the emotions were measured by the same factor. Participants who felt worried that they had hurt others also felt shame and anger directed at their self, as well as concern about others' opinions and feelings of having done wrong. The analyses did, however, distinguish two other shame-related emotions, embarrassment-exposure and unresolved shame, that had quite different characteristics from shame-guilt. Whereas shame-guilt predicted greater empathy and lower anger/hostility, both unresolved shame and embarrassment-exposure were associated with feelings of greater anger/hostility.

In contrast to these results, previous research has generally identified differences in the phenomenology of shame and guilt (Tangney, Miller et al., 1996; Wicker et al., 1983). The failure to distinguish between these emotions in the current study may be a function of the items used to measure these emotions. Although care was taken to represent those dimensions upon which shame and guilt are commonly differentiated, it is possible that participants did not interpret these questions as expected or that alternative dimensions are important. It is also possible that these results are a function of the specific context that participants were asked about. Drink-driving cases, and criminal justice cases more generally, involve the clear violation of a social norm (even if it is not universally accepted) and entail their own particular social processes (court or conference cases). Thus, the dimensionality found in these cases may not generalize to broader contexts in which these emotions occur.

However, another important difference between this study and other research is the methodology that was used. As discussed, other studies (Lindsay-Hartz, 1984; Miller \& Tangney, 1994; Niedenthal et al., 1994; Tangney, Miller et al., 1996; Wallbott \& Scherer, 1995; Wicker et al., 1983) have asked participants to recall their own memories of these emotions and then tested any differences. The memories that participants recalled, based upon their conceptions of the emotions, will be an important factor in how the emotions were characterized. The present study avoided having participants define the emotions. It did this by asking participants whether they had experienced specific feelings in a particular context. It may be that this procedure provides a better measure 
of how the emotions were experienced. If this is so, the results could be interpreted as showing that the conceptual distinctions previously found do not necessarily reflect the way in which the emotions are experienced in contexts where wrongdoing has occurred.

It is worth noting that the results reported here are not completely at odds with previous research, which also indicates some ambiguity in distinguishing shame from guilt. For example, Wicker et al. (1983) noted that differences between these emotions on their rating scales were mainly in degree rather than direction. Out of 68 scales, shame and guilt were only significantly different, and on opposite sides of the mid-point, on six scales. This led Wicker et al. (1983) to question whether the measured differences between shame and guilt were simply '. . . culturally transmitted conceptions of how shame and guilt differ...' (p. 38). The strength of the connection between shame and guilt is also apparent in the difficulty of empirical studies (Tangney, Miller et $a l ., 1996)$ to consistently distinguish between them on dimensions that have received the most theoretical attention.

If we accept that shame and guilt do occur as a single emotion within the types of court and conference cases observed, what does this suggest about their relationship? One conclusion might be that they are a single affective response that is labelled differently depending upon the context. For example, when no one else knows about something we have done, we might say that we feel guilt, but when everyone finds out we call it shame. This would be consistent with some theoretical perspectives. For example, affect theory (Kaufman, 1996; Nathanson, 1997; Tomkins, 1987) argues that a single negative affect, which moderates the positive affects of interest and joy, is the basis for all shame-related feelings. Another suggestion (Sabini \& Silver, 1997) is that guilt is not an emotion in itself but is a word used to describe how a person guilty of a wrong act feels, and that this often involves the emotion of shame.

Alternatively, the results could suggest that shame and guilt are complementary emotions that in some cases are indistinguishable. In response to a wrongdoing, an individual might feel a certain amount of 'guilt' that is focused upon their actions, but they would also experience some kind of negative self-evaluation (shame). The complementary nature of these emotions does make intuitive sense. If someone feels guilt for having hurt another person, it would seem odd if they did not also feel some shame, because their actions had threatened their perception of the kind of person they are, and their perception of how others judge them. Thus, we would expect that in many contexts both emotions will occur and will be in proportional intensity. This might be particularly true in criminological cases, such as the one studied here, where the event is given meaning by a specific wrongdoing. In other contexts individuals may feel negative self-evaluation without having something to also feel guilt about. However, in such cases we would need to distinguish between shame and low self-esteem (Leary \& Downs, 1995; Scheff, 1996).

Although the principal components analysis suggests that shame and guilt occurred together, they do not provide the means to test explanations, such as those discussed above. Other empirical techniques are needed to explore this question. The results do, however, suggest that the difference between shame and guilt may not be as important as some theoretical models have proposed. The implications of this for criminological interventions, and particularly restorative justice, are developed further in Ahmed, Harris, Braithwaite, and Braithwaite (2001).

Even though these results do not demonstrate the expected differences between shame and guilt, researchers and clinicians have observed important differences in the 
way that individuals respond to transgressions. This is particularly evident in work on shame- and guilt-proneness, which suggests that there are important differences between the disposition to focus negative evaluation on the act and on the self (Tangney, 1991). Perhaps the most important findings have been that shame-proneness (negative evaluation of the self) is related to dispositions to feel anger/hostility and lower empathy (Tangney, 1991; Tangney et al., 1992). However, in this study, shame-guilt, which involved feelings of anger and shame directed towards the self, was positively correlated with empathy and negatively correlated with anger/hostility.

An important difference between this study and research into shame-proneness is that the shame-guilt measure is situational rather than dispositional. Given the potential problems in generalizing between these levels of measurement, what the results may demonstrate is the importance of distinguishing between shame and shame-proneness. Shame-proneness identifies individuals who are more likely than others to respond to transgressions by feeling bad about themself. Especially in extreme cases, it is not surprising that such individuals are also more likely than others to respond by externalizing blame, feeling anger, and failing to feel empathy. What this study might show is that feelings of negative self-evaluation, when coupled with negative evaluation of the act and concern for the harm caused to others, are not problematic when felt in a specific context.

If feelings of 'shame' within specific contexts are not necessarily associated with anger and a lack of empathy, an important question is why proneness to feel shame appears to be such a problematic response. This question may be addressed by theoretical perspectives which argue that shame can be manifested in more or less healthy forms. For example, H. Lewis (1971) and Scheff and Retzinger (1991) identify by-passed shame as a response in which shame is not discharged or dealt with because it is never fully accepted. Nathanson (1992) also argues that individuals cope with shame in a variety of ways, one of which is to direct hostility towards others. The unresolved shame factor, identified in the factor analysis, may provide some evidence for this kind or response. Participants who felt unresolved shame were unable to resolve feelings relating to the shameful event and were more likely to feel anger and hostility towards other people who had attended their case. Research in other fields has also provided some evidence for the potential importance of shame management (Retzinger, 1991). For example, a study on school bullying has found that bullies are more likely to react to a shameful event by externalizing or rejecting shame, that victims are more likely to internalize shame without discharging it, and that non-bully non-victims are more likely to accept responsibility but in doing so discharge the shame (Ahmed, 2001).

These perspectives suggest that research may need to focus on variations in the way in which individuals manage the moral emotions. It may be that differences in the way individuals respond to failure reflect how they manage shame emotions, rather than differences in which emotion was felt. The negative self-evaluation associated with shame may only become problematic when it is not discharged. If this is the case, shameproneness might actually measure a disposition to internalize rather than discharge the negative self-evaluations arising in shame-guilt. Guilt-proneness would be the disposition to manage shame-guilt effectively by discharging negative evaluation.

The finding that shame and guilt were not distinguished between is in contrast to theoretical and empirical models that emphasize their distinctiveness. However, this study only examines these emotions in one context, which may be unique because of its criminological subject or the particular offence type. Further empirical work is needed to determine whether this dimensionality reliably predicts shame, guilt and 
embarrassment when measured within different contexts. Equally significant are questions regarding the relationship between shame and shame-proneness. If shameguilt is not associated with emotional reactions like anger and hostility, then how does shame come to be a maladaptive disposition? One answer that may deserve further attention is that there are differences in how people manage their feelings of shame and guilt.

\section{Acknowledgements}

The data used in this paper were collected as part of the ReIntegrative Shaming Experiments (RISE) in Canberra, Australia. This project was funded by the Criminology Research Council, Federal Office of Road Safety, National Drug Crime Prevention Fund, Australian National University Strategic Planning Fund and the Australian Research Counsel. I am indebted to all those associated with the RISE project who made collection of the data possible, particularly Lawrence Sherman and Heather Strang. I also wish to thank colleagues at the Australian National University and the Katholieke Universiteit Leuven for their valuable comments and insights; in particular John Braithwaite, Val Braithwaite, Eliza Ahmed, Lode Walgrave and Inge Vanfraechem, as well as the anonymous reviewers for their suggestions.

\section{References}

Ahmed, E. (2001). Shame management: Regulating bullying. In E. Ahmed, N. Harris, J. Braithwaite, \& V. Braithwaite (Eds.), Shame management through reintegration (pp. 210-330). Cambridge: Cambridge University Press.

Ahmed, E., Harris, N., Braithwaite, J., \& Braithwaite, V. (2001). Shame management through reintegration. Cambridge: Cambridge University Press.

Baumeister, R. F., Stillwell, A. M., \& Heatherton, T. F. (1995). Interpersonal aspects of guilt: Evidence from narrative studies. In J. P. Tangney \& K. W. Fischer (Eds.), Self conscious emotions: The psychology of shame, guilt, embarrassment, and pride (pp. 255-273). New York: Guilford Press.

Benedict, R. (1946). The chrysanthemum and the sword: Patterns of Japanese culture. Boston: Houghton Mifflin.

Braithwaite, J. (1989). Crime, shame and reintegration. Cambridge: Cambridge University Press. Buss, A. H. (1980). Self-consciousness and social anxiety. San Francisco: Freeman.

Cattell, R. B. (1966). The scree test for the number of factors. Multivariate Behavioural Research, $1,245-276$.

Crozier, W. R. (1990). Social psychological perspectives on shyness, embarrassment and shame. In W. R. Crozier (Ed.), Shyness and embarrassment: Perspectives from social psychology. Cambridge: Cambridge University Press.

Duval, S., \& Wicklund, R. A. (1972). A theory of objective self awareness. New York: Academic Press.

Edelmann, R. J. (1987). The psychology of embarrassment. Chichester, UK: Wiley.

Edelmann, R. J., Asendorpf, J., Contarello, A., Zammuner, V., Georgas, J., \& Villanueva, C. (1989). Self-reported expressions of embarrassment in five European cultures. Journal of CrossCultural Psychology, 20(4), 357-371.

Epstein, A. L. (1984). The experience of shame in Melanesia. London: Royal Anthropological Institute of Great Britain and Ireland.

Freud, S. (1949/1930). Civilization and its discontents. London: Hogarth.

Gibbons, F. X. (1990). The evolution and manifestation of social anxiety. In W. R. Crozier (Ed.), Shyness and embarrassment: Perspectives from social psychology. Cambridge: Cambridge University Press. 
Gilbert, P. (1997). The evolution of social attractiveness and its role in shame, humiliation, guilt and therapy. British Journal of Medical Psychology, 70, 113-147.

Gorsuch, R. L. (1983). Factor analysis. Hillsdale, NJ: Erlbaum.

Grasmick, H. G., \& Bursik, R. J. (1990). Conscience, significant others, and rational choice: Extending the deterrence model. Law and Society Review, 24(3), 837-861.

Harder, D. W. (1995). Shame and guilt assessment, and relationships of shame- and guiltproneness to psychopathology. In J. P. Tangney \& K. W. Fischer (Eds.), Self conscious emotions: The psychology of shame, guilt, embarrassment, and pride (pp.368-392). New York: Guilford.

Harder, D. W., Cutler, L., \& Rockart, L. (1992). Assessment of shame and guilt and their relationships to psychopathology. Journal of Personality Assessment, 59, 584-604.

Harré, R. (1990). Embarrassment: A conceptual analysis. In W. R. Crozier (Ed.), Shyness and embarrassment: Perspectives from social psychology. Cambridge: Cambridge University Press.

Kaufman, G. (1996). The psychology of shame: Theory and treatment of shame-based syndromes (2nd ed.). New York: Springer.

Leary, M. R. (2000). Affect, cognition, and the social emotions: A theory of relational devaluation. In J. P. Forgas (Ed.), Feeling and thinking: The role of affect in social cognition. Cambridge: Cambridge University Press.

Leary, M. R., \& Downs, D. L. (1995). Interpersonal functions of the self-esteem motive: The selfesteem system as a sociometer. In M. H. Kernis (Ed.), Efficacy, agency, and self esteem: Plenum series in social/clinical psychology (pp. 123-144). New York: Plenum.

Lewis, H. B. (1971). Shame and guilt in neurosis. New York: International Universities Press.

Lewis, M. (1992). Shame: The exposed self. New York: Free Press.

Lindsay-Hartz, J. (1984). Contrasting experiences of shame and guilt. American Behavioural Scientist, 27, 689-704.

Mead, M. (1937). Cooperation and competition among primitive peoples. New York: McGrawHill.

Miller, R. S. (1992). The nature and severity of self-reported embarrassing circumstances. Personality and Social Psychology Bulletin, 18(2), 190-198.

Miller, R. S. (1995). Embarrassment and social behaviour. In J. P. Tangney \& K. W. Fischer (Eds.), Self-conscious emotions: The psychology of shame, guilt, embarrassment, and pride. New York: Guilford.

Miller, R. S., \& Tangney, J. P. (1994). Differentiating embarrassment and shame. Journal of Social and Clinical Psychology, 13(3), 273-287.

Nathanson, D. L. (1992). Shame and pride: Affect, sex and the birth of the self. New York: W. W. Norton.

Nathanson, D. L. (1997). Affect theory and the compass of shame. In M. R. Lansky (Ed.), The widening scope of shame (pp. 339-354). Hillsdale, NJ: Analytic Press.

Niedenthal, P. M., Tangney, J. P., \& Gavanski, I. (1994). 'If only I weren't' versus 'If only I hadn't': Distinguishing shame and guilt in counterfactual thinking. Journal of Personality and Social Psychology, 67(4), 585-595.

Piers, G., \& Singer, M. B. (1953). Shame and guilt: A psychoanalytic and a cultural study. New York: Norton.

Retzinger, S. M. (1991). Violent emotions: Shame and rage in marital quarrels. Newbury Park, CA: Sage.

Sabini, J., Garvey, B., \& Hall, A. L. (2001). Shame and embarrassment revisited. Personality and Social Psychology Bulletin, 27(1), 104-117.

Sabini, J., \& Silver, M. (1997). In defence of shame: Shame in the context of guilt and embarrassment. Journal for the Theory of Social Behaviour, 27(1), 1-15.

Sachdev, P. S. (1990). Whakama: Culturally determined behaviour in the New Zealand Maori. Psychological Medicine, 20(2), 433-444. 
Scheff, T. J. (1990). Microsociology: Discourse, emotion, and social structure. Chicago: University of Chicago Press.

Scheff, T. J. (1996). Self-esteem and shame: Unlocking the puzzle. In R. Kwan (Ed.), Individuality and social control: Essays in bonour of Tamotsu Shibutani. Greenwich, CT: JAI.

Scheff, T. J., \& Retzinger, S. M. (1991). Emotions and violence: Shame and rage in destructive conflicts. Lexington, MA: Lexington Books/D. C. Heath.

Sherman, L., Braithwaite, J., \& Strang, H. (1994). Reintegrative shaming of violence, drinkdriving and property crime: A randomised controlled trial. Unpublished manuscript.

Tabachnick, B. G., \& Fidell, L. S. (2001). Using mulitivariate statistics (4th ed.). Boston: Allyn and Bacon.

Tangney, J. P. (1991). Moral affect: The good, the bad, and the ugly. Journal of Personality and Social Psychology, 61(4), 598-607.

Tangney, J. P., Miller, R. S., Flicker, L., \& Hill-Barlow, D. H. (1996). Are shame, guilt, and embarrassment distinct emotions? Journal of Personality and Social Psychology, 70(6), $1256-1269$.

Tangney, J. P., Wagner, P., Fletcher, C., \& Gramzow, R. (1992). Shamed into anger? The relation of shame and guilt to anger and self-reported aggression. Journal of Personality and Social Psychology, 62(4), 669-675.

Tangney, J. P., Wagner, P. E., \& Gramzow, R. (1989). The Test of Self Conscious Affect (TOSCA). Fairfax, VA: George Mason University.

Tangney, J. P., Wagner, P. E., Hill-Barlow, D., Marschall, D. E., \& Gramzow, R. (1996). Relation of shame and guilt to constructive versus destructive responses to anger across the lifespan. Journal of Personality and Social Psychology, 70(4), 797-809.

Taylor, G. (1985). Pride, shame and guilt: Emotions of self-assessment. Oxford: Oxford University Press.

Tomkins, S. S. (1987). Shame. In D. L. Nathanson (Ed.), The many faces of shame (pp. 133-161). New York: Guilford.

Wallbott, H. G., \& Scherer, K. R. (1995). Cultural determinants in experiencing shame and guilt. In J. P. Tangney, \& K. W. Fischer (Eds.), Self conscious emotions: The psychology of shame, guilt, embarrassment, and pride (pp. 465-487). New York: Guilford Press.

Wicker, F. W., Payne, G. C., \& Morgan, R. D. (1983). Participant descriptions of guilt and shame. Motivation and Emotion, 7, 25-39.

Williams, B. (1993). Shame and necessity. Berkeley, CA: University of California Press.

Wurmser, L. (1994). The mask of shame. Northvale, NJ: Jason Aronson.

Received 3 May 2002; revised version received 27 November 2002 